\title{
The role of abiotic and anthropogenic factors in the development of Alternaria leaf spot on potato plantings in the North-West of Russia
}

\author{
Alexander Shpanev*, and Vasiliy Smuk \\ All-Russian Institute of Plant Protection, 196608, 3, Podbelsky highway, Saint-Petersburg, \\ Russian Federation
}

\begin{abstract}
For effective control of the phytosanitary state of agrocenoses, it is important to have knowledge of the influence of abiotic and anthropogenic factors on the population density of pests, weeds and the development of diseases. Among all the factors influencing the development of Alternaria leaf spot in potato planting in the North-West of Russia, the most significant was the influence of weather conditions $(55.5 \%)$. The intense development of this illness occurred in the years with the high average diurnal temperatures in the second and third decades of June along with the high level of precipitation in the first decade of July. The contribution of mineral nutrition and the integrated plant protection system turned out to be unequal, which accounted for 9.6 and $0.9 \%$. At the same time, in some years, the application of mineral fertilizers determined the development of potato Alternaria leaf spot by $11.6-87.5 \%$, and the implementation of protective measures - by $1.2-17.6 \%$. The strong development of Alternaria leaf spot was influenced by the increased air temperatures in the second and third decades of June, combined with abundant humidity in the first decade of July. The introduction of complete mineral fertilization led to a significant decrease in the development of Alternaria leaf spot in potato plantings, while the effectiveness of fungicidal treatments was not high enough.
\end{abstract}

\section{Introduction}

Alternaria leaf spot is the most common potato disease worldwide. According to the data of native and foreign researchers, the infection of potato plantings with Alternaria can lead to a decrease in yield by $10-50 \%[1,2]$. On the territory of the Russian Federation, the greatest harm caused by Alternaria is recorded in the Baikal region and the Far East, where potato yield losses can reach $40-50 \%$ [3]. In recent years, due to climate warming, an increase in the area and zones of harm caused by Alternaria leaf spot has been observed, both in Russia and abroad [4-6]. This trend is also relevant for the North-West region, due to its natural and climatic conditions it does not belong to the region of high infection with

\footnotetext{
*Corresponding author: ashpanev@mail.ru
} 
Alternaria, but in the case of epiphytotic development of the disease, the decrease in potato productivity can be significant (up to $30 \%$ ) [7].

One of the main factors for the development of Alternaria is the increased air temperature during the active growing season of potatoes [4]. The factors limiting the development of Alternaria on potato plantings include resistant varieties and the supply of plants with the basic elements of mineral nutrition. So, it is known about the positive effect of increased standards of nitrogen (90-100 kg/ha) and potassium, and about the negative effect of phosphor excess in the soil on the manifestation of this disease in potatoes $[8,9]$.

This work examines the results of a long-term study of the influence of abiotic (weather conditions) and anthropogenic (mineral fertilizers, fungicide treatment) factors on the development of Alternaria in potato plantings in North-West Russia.

\section{Methods}

The studies were carried out in the period of 2014-2021 on potato plantings of the Menkovsky branch of the Agrophysical Research Institute (Leningrad Region, Gatchinsky District), which is one of the largest experimental bases in the sphere of agriculture in the North-West region [10].

During 2014-2020 the research focused on a seven-field grain-herbal row crop rotation, in which potatoes are placed after two years of perennial grasses cultivation (timothy grass + red clover). The soil is turfy weak podzolic light loamy soils, the thickness of the arable layer is $23 \mathrm{~cm}, \mathrm{pHKCl}$ is 4.6 , the humus content (according to Tyurin [11]) is $1.9 \%$, mobile compounds of phosphorus and potassium (according to Kirsanov [12]) are 257 and $92 \mathrm{mg}$ $\mathrm{kg}$, respectively.

Within the station three levels of mineral nutrition (LMN) - low (without fertilizers), medium (N65P50K50) and high (N100P75K75) - have been created and are maintained by a long-term annual pre-sowing introduction of azophoska and ammonium nitrate based on the planned yield of cultivated crops.

We also studied the integrated plant protection system (IPPS), according to which protective measures against pests were carried out provided that the economic threshold of harmfulness was exceeded. The integrated protection system of potato plantings consisted of seed dressing, 4 soil treatments with a rotary harrow, hilling and one-time introduction of herbicides, 3-4 treatments of vegetative plants with fungicides, desiccation.

Observations of the development of Alternaria in potato plantings were carried out on marked permanent registration areas of $1.4 \mathrm{~m}^{2}$, placed on the field according to the experimental scheme. In each variant, 6 permanent sites were installed, in total, 36 according to the experiment, 252 during all years of research. Characteristics of the disease included an assessment of the incidence, intensity of damage and development, expressed in relative terms. During the growing season, the density and height of potato plants were recorded at permanent registration plots; at the end of the growing season, a structural assessment of the crop yield was carried out.

The analysis of the temperature mode during the active growing season of potatoes revealed a stable long-term increase in this indicator relative to the average long-term level in the range from 3 to $13 \%$. The only exception to this trend was the year 2017 , the level of heat supply of which was $96 \%$ of the average long-term norm. In 2015, the sums of active temperatures were at the level of long-term values. According to the amount of rainfall, the growing season of 2016 turned out to be excessively humid. The excess of the long-term average value for this index was 53\%. Only the years 2014 and 2015 can be considered arid, when the total amount of rainfall over the summer period was at the level of 73 and 
$61 \%$ of the average long-term humidity norm. The years $2017-2019$ turned out to be the closest to the average long-term indices.

Statistical processing of the data obtained consisted of dispersion and correlation analyzes carried out in the Statistica 6.0 software.

\section{Results}

As a result of our research, the effect of high temperatures on the level of development of Alternaria leaf spot in potato plantings was confirmed. Thus, the smallest development of the pathogen was observed in 2017 under conditions of the worst heat supply, and the largest - in 2018. (table 1). The sums of active temperatures in these years amounted to 96 and $111 \%$ of the long-term average values. It should be noted that the presence of only high temperatures for the successful development of this pathogen in potato plantings is not enough. Thus, in the conditions of extremely dry July and early August of 2014, the development of Alternaria was moderate (10.6\%), despite the long-term favorable temperature mode. Thus, the lack of sufficient moisture in potato plantings at a certain stage of the growing season can also significantly affect the degree of manifestation of Alternaria in potato plantings. According to the results of the correlation analysis, a strong development of the disease can be expected in the case of high average daily temperatures in the second and third decades of June $(r=0.70$ and 0.63$)$ together with abundant moisture in the first decade of July $(r=0.66)$. To an even greater extent, the positive impact of the June drought can be seen when analyzing the seasonal dynamics of the hydrothermal coefficient (HTC). The value of this integral indicator in the third decade of June $(r=-0.74)$ and the first decade of July $(r=0.63)$ can statistically determine the level of the final development of Alternaria in potato plantings.

Table 1. Long-term dynamics of meteorological conditions and the development of Alternaria in potato plantings in the North-West of Russia.

\begin{tabular}{|l|c|c|c|c|c|c|c|}
\hline \multirow{2}{*}{\multicolumn{1}{|c|}{ Indicators }} & \multicolumn{7}{c|}{ Year } \\
\cline { 2 - 8 } & $\mathbf{2 0 1 4}$ & $\mathbf{2 0 1 5}$ & $\mathbf{2 0 1 6}$ & $\mathbf{2 0 1 7}$ & $\mathbf{2 0 1 8}$ & $\mathbf{2 0 1 9}$ & $\mathbf{2 0 2 0}$ \\
\hline The sum of active temperatures, ${ }^{\circ} \mathrm{C}$ & 1511 & 1397 & 1465 & 1339 & 1550 & 1465 & 1524 \\
Amount of precipitation, mm & 170 & 140 & 353 & 237 & 240 & 243 & 392 \\
Hydrothermal coefficient & 1.3 & 1.0 & 2.3 & 2.1 & 1.5 & 1.8 & 2.6 \\
Disease development, \% & 10.6 & 13.9 & 39.4 & 3.1 & 52.8 & 35.0 & 17.3 \\
\hline
\end{tabular}

According to the results of the studies, it was revealed that with an increase in mineral nutrition, there was a decrease in the level of development of Alternaria on potato plants. According to our data, the development of Alternaria in the cultivars Sudarynya and Udacha in the unfertilized variant exceeded the indicators of the fertilized variants by 1.5 2.0 and 1.6-2.1 times, respectively. According to the statistical processing carried outin the Sudarynya cultivar, there were significant differences in the infection of Alternaria and the development of the disease between the unfertilized and highly fertilized variants; in Udacha cultivar in the intensity of damage and development between the unfertilized, medium and highly fertilized variants (table 2). At the same time, on both varieties, there were no significant differences in the development of Alternaria between medium and highly fertilized experimental plots.

The first signs of Alternaria were always recorded on unfertilized plots, while on fertilized ones $-7-10$ days later. In the years of weak development of the disease, this occurred during the blooming and tuber growth phases, respectively. At the same time, plants located on plots, where a high dose of complete mineral fertilization was applied, remained unaffected by Alternaria throughout the entire growing season of potatoes. In 
years favorable for the development of Alternaria, the affected leaves were found on the unfertilized version already in the bud formation phase, and in blooming - in all variants of the experiment, including the highly fertilized one. During this period, on unfertilized plots, the development of Alternaria was already $25 \%$, and at the time of desiccation it increased to $65 \%$; on medium and highly fertilized plots it increased up to 52 and $42 \%$, i.e. $2.6,4.4$ and 8.3 times (table 3). This means that in such years, a strong damage to potatoes by Alternaria occurs regardless of mineral nutrition, although significant differences between variants of fertilization remain.

Table 2. The influence of mineral fertilizers on the development of Alternaria in potato plantings.

\begin{tabular}{|l|c|c|c|}
\hline \multirow{2}{*}{\multicolumn{1}{|c|}{ Indicators }} & \multicolumn{3}{|c|}{ Fertilizer doses } \\
\cline { 2 - 4 } & N0P0K0 & N65P50K50 & N100P75K75 \\
\hline Variety Sudarynya & & & \\
Affected plants, \% & 95.8 & $83.3^{*}$ & $75.0^{*}$ \\
Intensity of damage, \% & 24.1 & $19.0^{*}$ & $15.0^{*}$ \\
Disease development, \% & 23.1 & $15.8^{* *}$ & $11.3^{* *}$ \\
\hline Variety Udacha & & & \\
Affected plants, \% & 100 & 100 & 100 \\
Intensity of damage, \% & 50.6 & $30.5^{* *}$ & $23.9^{* *}$ \\
Disease development, \% & 50.6 & $30.5^{* *}$ & $23.9^{* *}$ \\
\hline
\end{tabular}

Note: * - differences are significant at $\mathrm{P} \geq 0.95, * *-\mathrm{P} \geq 0.99$.

Received data for the period of 2018 till 2020 years on susceptible potato cultivar Udacha showed low efficiency of fungicide protection of plants against Alternaria. Schemes for the use of fungicides included three treatments with preparations with the following alternation: 2018 and 2019 - Ridomil Gold MC, VDG (twice), Sectin Phenomenon, VDG; 2020 - Sectin Phenomenon, VDG (twice), Acrobat MC, VDG. It is important to note that these schemes were effective against late blight, as the main and most harmful disease of potatoes in the region, and the development of Alternaria was reduced at the level of $16.9-31.7 \%$ (fig. 1).
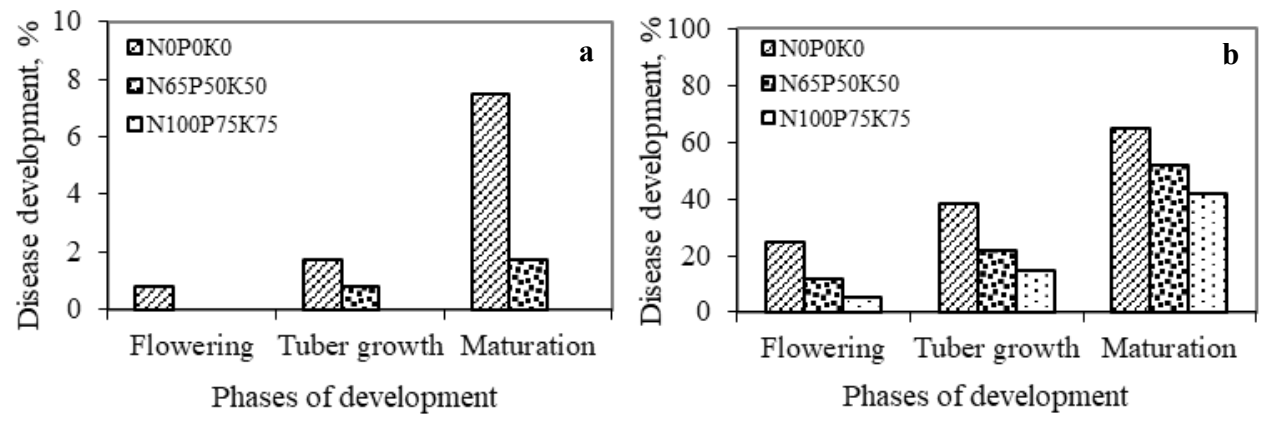

Fig. 1. Dynamics of damage to potato plants by Alternaria during the years of its weak (a) and strong (b) development.

Received data for the period of 2018 till 2020 years on susceptible potato cultivar Udacha showed low efficiency of fungicide protection of plants against Alternaria. Schemes for the use of fungicides included three treatments with preparations with the following alternation: 2018 and 2019 - Ridomil Gold MC, VDG (twice), Sectin Phenomenon, VDG; 2020 - Sectin Phenomenon, VDG (twice), Acrobat MC, VDG. It is important to note that these schemes were effective against late blight, as the main and most 
harmful disease of potatoes in the region, and the development of Alternaria was reduced at the level of $16.9-31.7 \%$ (table 3 ).

Table 3. Biological effectiveness of fungicidal treatments against potato Alternaria in the North-West of Russia.

\begin{tabular}{|l|c|c|c|c|c|c|}
\hline \multirow{2}{*}{$\begin{array}{c}\text { Experience } \\
\text { options }\end{array}$} & \multicolumn{2}{|c|}{ 2018 year } & \multicolumn{2}{c|}{ 2019 year } & \multicolumn{2}{|c|}{ 2020 year } \\
\cline { 2 - 7 } & $\begin{array}{c}\text { Disease } \\
\text { developme } \\
\text { nt, \% }\end{array}$ & $\begin{array}{c}\text { Decreased } \\
\text { developme } \\
\text { nt,\% }\end{array}$ & $\begin{array}{c}\text { Disease } \\
\text { developme } \\
\text { nt, \% }\end{array}$ & $\begin{array}{c}\text { Decreased } \\
\text { developme } \\
\text { nt, \% }\end{array}$ & $\begin{array}{c}\text { Disease } \\
\text { developme } \\
\text { nt, \% }\end{array}$ & $\begin{array}{c}\text { Decreased } \\
\text { developme } \\
\text { nt,\% }\end{array}$ \\
\hline $\begin{array}{l}\text { No fungicide } \\
\text { treatments } \\
\begin{array}{l}\text { Three fungicidal } \\
\text { treatments }\end{array}\end{array}$ & 52.8 & - & 35.0 & - & 17.0 & - \\
\hline
\end{tabular}

According to the data obtained, the variation in the development of Alternaria in potato plantings over the years ranged from 3.1 to $52.8 \%$ with an average value of $24.6 \%$. The high degree of variation was mainly determined by the weather conditions of the growing season. The influence of this factor accounted for $55.5 \%$, while the total contribution of abiotic and anthropogenic factors to the development of this disease was $66 \%$. Based on the identified interactions, the influence of weather conditions extended to the effects associated with improvement in the mineral nutrition of potato plants (table 4). This was also statistically confirmed. In other words, a reliable influence of weather conditions on the efficiency of the applied mineral fertilizers and on the development of Alternaria, was revealed.

Table 4. Contribution of abiotic and anthropogenic factors to the development of potato alternaria in in the North-West of Russia.

\begin{tabular}{|l|c|}
\hline \multicolumn{1}{|c|}{ Factor } & Share, $\%$ \\
\hline Weather conditions (Year) & $55.5^{*}$ \\
Mineral Nutrition Level (MNL) & $9.6^{*}$ \\
Integrated Plant Protection System (IPPS) & $0.9^{*}$ \\
Interactions Year + MNL & $7.2^{*}$ \\
Interactions Year + IPPS & 1.3 \\
Interactions MNL + IPPS & 0.1 \\
Interactions Year + MNL + IPPS & 0.8 \\
Iteration & 0.8 \\
Random & 23.7 \\
\hline
\end{tabular}

Note: * - differences are significant at $\mathrm{P} \geq 0.95$.

The contribution of mineral nutrition and the integrated system of plant protection to the development of potato Alternaria turned out to be unequal, which accounted for 9.6 and $0.9 \%$. The data obtained confirm the low efficiency of fungicidal treatments of growing plants in relation to Alternaria. In some years, the application of mineral fertilizers determined the development of potato Alternaria by $11.6-87.5 \%$, and the implementation of protective measures - by $1.2-17.6 \%$. The interaction of mineral fertilizers and plant protection products when influencing the yield of potatoes reached $4.0-5.2 \%$ in some years or decreased to $0.3-1.6 \%$ (table 5 ). 
Table 5. Contribution of anthropogenic factors to the development of potato alternaria in different years in the North-West of Russia.

\begin{tabular}{|l|c|c|c|c|c|c|c|}
\hline \multirow{2}{*}{\multicolumn{1}{|c|}{ Factor }} & \multicolumn{7}{c|}{ Year } \\
\cline { 2 - 8 } & $\mathbf{2 0 1 4}$ & $\mathbf{2 0 1 5}$ & $\mathbf{2 0 1 6}$ & $\mathbf{2 0 1 7}$ & $\mathbf{2 0 1 8}$ & $\mathbf{2 0 1 9}$ & $\mathbf{2 0 2 0}$ \\
\hline Mineral Nutrition Level (MNL) & 11.6 & $74.1^{*}$ & $69.5^{*}$ & $26.6^{*}$ & $24.6^{*}$ & $40.5^{*}$ & $87.5^{*}$ \\
Integrated Plant Protection System (IPPS) & 1.8 & 2.1 & $17.6^{*}$ & 3.5 & $9.4^{*}$ & $15.2^{*}$ & 1.2 \\
Interactions MNL + IPPS & 0.9 & $5.2^{*}$ & $4.2^{*}$ & 4.0 & 4.7 & 0.3 & 1.6 \\
\hline
\end{tabular}

Note: * - differences are significant at $\mathrm{P} \geq 0.95$.

\section{Discussion}

As a result of our research, the well-known idea from the literature has been confirmed that the main factor for the strong development of Alternaria in potato is the increased temperature background during the active growing season of potatoes [4]. It is also well known that high temperatures have a strong positive effect on the timing of the appearance and degree of development of Alternaria in potato agrocenosis [3, 13]. The intense development of this illness occurred in the years with the high average diurnal temperatures in the second and third decades of June along with the high level of precipitation in the first decade of July.

According to the results of the studies, it was revealed that with an increase in mineral nutrition, there was a decrease in the level of development of Alternaria on potato plants. This regularity found statistical confirmation in both studied cultivars, and it fully agrees with the published data, from which it is known about the positive effect of nitrogen and organic fertilizers on the resistance of potato plantings to Alternaria [14-16]. The increase in resistance under the influence of fertilizers is due to a decrease in the permeability of cell membranes, an increase in the osmotic pressure of the cell sap, the content of dry substances and reducing sugars in it, which creates unfavorable conditions for the spread of the pathogen in plant tissues [8]. In addition, the infectious agents of Alternaria are typical necrotrophs, affecting weakened due to a lack of nutrients, and aging plants $[4,17]$.

Thus, the most difficult situation with of Alternaria develops on susceptible varieties and non-maneuverable potato plantings, which is further aggravated due to the low effectiveness of fungicidal treatments with drugs widely used in the region. These primarily include Ridomil Gold MC, VDG; Sectin Phenomenon, VDG and Acrobat MC, VDG, the spectrum of fungicidal activity of which extends to late blight and Alternaria in potato.

Further research prospects are related to the study of the effectiveness of protection schemes for vegetative potato plants containing drugs aimed at suppressing the development of Alternaria in potato. For example, it is known from the literature about the positive experience of using sequential triple treatment against Alternaria with Revus Top, SK, Penncoceb, SP and Signum, VDG in epiphytotic conditions [18].

\section{Conclusion}

Thus, the strongest influence on the development of Alternaria in potato planting in NorthWest Russia is caused by weather conditions; it is also applied to the effects associated with the use of mineral fertilizers. The total contribution of anthropogenic factors (mineral nutrition and integrated plant protection system) is estimated at $10.5 \%$, with their unequal share in the development of potato Alternaria. The introduction of complete mineral fertilization led to a significant decrease in the development of Alternaria in potato 
plantings, while the effectiveness of fungicidal treatments was not high enough. The combined effect of abiotic and anthropogenic factors was $66 \%$.

\section{References}

1. N.F. Deniskina, O.N. Ivashova, I.N. Gasparyan, A.G. Levshin, M.E. Dyikanova, IOP Conference Series: Earth and Environmental Science, 723 (2021)

2. J. Kapsa, J. Osowski, PPO-Special Report, 10 (2004)

3. M.S. Kvasnikova, Potatoes in the Far East. Vladivostok (1976)

4. B.E. Kozlovsky, A.V. Filippov, Plant Protection and Quarantine, 5 (2007)

5. J. Schmiede, Agrozucker und Agrostarke, 3 (2007)

6. O. Escuredo, A. Seijo-Rodríguez, L. Meno, M.S. Rodríguez-Flores, M.C. Seijo, American Journal of Potato Research, 96 (2019)

7. M.I. Boyko, Macrosporiosis of potatoes and tomatoes and measures to combat it in the conditions of the Leningrad region (Leningrad, 1954)

8. V.G. Ivanyuk, D.I. Yagneshko, Problems of plant nutrition and the use of fertilizers in modern conditions (Minsk, 2000)

9. E.S. Melnikova, E.A. Melkumova, Phytosanitary optimization of agroecosystems (St. Petersburg, 2013)

10. A. Shpanev, Modern problems of remote sensing of the Earth from space, 16, 3 (2019)

11. GOST 26213-91 Soil, Methods for determining organic matter (Moscow, 1992)

12. GOST R 54650-2011 Soil, Determination of mobile compounds of phosphorus and potassium by the Kirsanov method in the modification of the TsINAO (Moscow, 2013)

13. K.V. Popkova, Yu.I. Schneider, A.S. Volovik, V.A. Shmyglya, Potato diseases (Moscow, 1980)

14. L. Wiik, Applied Plant Research Wageningen, 10 (2004)

15. A. Shpanev, V. Smuk, M. Fesenko, Agrochemistry, 12 (2017)

16. I.K. Abuley, B.J. Nielsen, H.H. Hansen, Pest management science, 75 (2019)

17. J. Rotem, Israel journal of botany, 15 (1966)

18. M.A. Kuznetsova, I.A. Denisenko, A.N. Rogozhin, T.I. Smetanina, V.N. Demidova, N.V. Statsyuk, Modern approaches and methods in plant protection (Yekaterinburg, 2020) 